Arab World English Journal (AWEJ) Volume 12. Number4 December 2021

DOI: https://dx.doi.org/10.24093/awej/vol12no4.27

Pp. $415-425$

\title{
Improving Classroom Observation through Training: A qualitative Study in College of Technology in Oman
}

\author{
Haroun Mohammed Abdullah AL-Balushi \\ English Language Center \\ University of Technology \& Applied Sciences \\ Ibra- Sultanate of Oman \\ Corresponding Author: hms3501@gmail.com \\ Noor Saazai bt Mat Saad \\ Faculty of Major Languages Studies Malaysia \\ University Sains Islam Malaysia, Malaysia
}

Received: 9/6/2021

Accepted: 11/18/2021

Published: 12/15/2021

\begin{abstract}
Historically, classroom observations have been conducted in educational establishments for different purposes such as evaluation of teachers, promotion, curriculum design, or professional development. In this study, the researchers aimed to improve the effectiveness of the classroom observation process in an English Language Center based in a College of Technology in the Sultanate of Oman. The study adopted a qualitative research methodology and semi-structured interviews as the data collection tool. In the first stage, observers and teachers were interviewed to understand the existing classroom observation process. Based on the initial data, a training program was developed with materials from international good practice projects. Finally, the changes were identified through the second set of interviews with the participants. The major results of this study suggest that the training program contributed positively to the perceived effectiveness of the classroom observation process, reduced anxiety related to this process, and led to more balanced participation from both the observers and the teachers. Moreover, the implementation of the pre-observation conferences started taking place and post-observation meetings included more constructive feedback. This study adds to the literature on the importance of classroom observation training with a practical training program. This practical approach can be adopted in similar contexts with some adaptation to meet the specific needs of educational institutions. The researchers suggest a qualitative research approach to accompany any such future training to measure the effects of the training program.

Keywords: classroom observation, college of technology in Oman, non-directive approach, preobservation conference, training program

Cite as: AL-Balushi, H. M. A., \& Mat Saad, N.S. (2021). Improving Classroom Observation through Training: A qualitative Study in College of Technology in Oman. Arab World English Journal, 12 (4) 415-425. DOI: https://dx.doi.org/10.24093/awej/vol12no4.27
\end{abstract}




\section{Introduction}

Classroom observation can play an essential role in improving teachers' performance. Many researchers in the field of education mentioned that classroom observation is a tool for professional development, although this mainly depends on the way observations are carried out. In fact, classroom observation can also be a real concern and a cause of failure for many teachers if it is not applied effectively. A high level of anxiety negatively affects teachers' performance and extends its impact on the learning process in general. Therefore, it is important to make sure that those who perform the classroom observation are competent and able to perform this task professionally without causing negative feelings such as anxiety or fear.

\subsection{History of Class Observation}

The classroom observation process has gone through many different stages and variables (Olivia et al., 1997). The term inspection was used for the period from 1830 to 1850. This phase was characterized as a police phase where the purpose of the classroom observation process was to discover deficiencies and teachers' mistakes and determine whether teachers were applying the rules. The responsibility for carrying out this task rested with a committee made up of fathers, clergy and citizens. As for the next stage, it extended from 1850 to 1910 and adopted another term called Instructional improvement. In this period, the focus was on teachers and enhancing their ability to teach. However, from 1910 to 1930, classroom observation was called scientific and bureaucratic. The focus during this period was on improving the performance of teachers and enabling them to perform their work in the best way. The responsibility for carrying out the supervision task at this stage was assigned to each supervisor from the central office and the school principal. For the period from 1930 - 1950, the purpose of the observation process was mainly to improve the quality of teaching. This stage adopted the term human relations. However, from 1950-1970, monitoring became bureaucratic, scientific, clinical and humanistic relationships. A supervisor from the central office and the principal of the school were assigned to carry out this task in addition to a mentor responsible for supporting the teachers and providing them with suggestions to improve their performance in the classroom. It should also be noted here that in this stage the use of terms, collegial, collaborative, peer, coach and mentorship, were added as types of supervision that contribute to the improvement of teaching, learning and student achievement.

Goldhammer, Anderson and Krajewski (1980) also shed light on the supervision methods that appeared in the professional literature between 1850 and 1990. They classified them as scientific management, democratic interaction approach, cooperative supervision, supervision as curriculum development, clinical supervision, group dynamics and peer focus, training and educational supervision. In terms of the modern approaches to supervision, Duffy (1997) states that two types of supervision are the leading ones, namely clinical supervision and administrative control. On the other hand, Goldsberry (1988) presented three models of modern educational supervision: nominal, corrective, and reflective.

\subsection{Training for classroom observation}

Classroom observation is one of the effective methods used by educators to develop the teaching and learning process. Classroom observation has been defined as a process during which the observer sits in one or more study sessions, records the teacher's teaching practices and students' actions, and then meets with the teacher to discuss the observations (Wragg, 1999). 
Wilcox (2000) regards classroom observation as a primary method of collecting data on what is happening in the classroom. Observation is used as an opportunity to observe experienced teachers. With teachers on duty, observation is usually part of the supervision process. The supervisor visits the teacher's class, observes the lesson and provides feedback on its effectiveness. Marshall (2009) argued that classroom observation is a form of professional development that allows critical pieces of teachers' knowledge and skills to converge in a real opportunity to gain insight into the quality of the learning experiences that are being provided. Gordove (2002) believes that any observation of lessons should be the basis for professional development.

One of the basic concepts that this study is based upon is that supervision and observation should be deemed a process leading to the professional development of teaching staff. The researcher designed a training program based on the respondents' perceptions and their implementation of the classroom observation process with the aim of increasing awareness of internationally accepted good practices in this field.

As a general practice, observation is associated with evaluation, which is why particularly with teachers in service - it often has negative connotations (Freeman, 1982). Therefore, Ruth (2003) believes it is necessary to nominate a qualified person who can conduct the monitoring process professionally. Mulyasa (2007) argues for a new model of educational management that principals should be at least able to play the role of teacher, principal, principal, supervisor, leader, innovator, and motivator. The study also confirms the finding in the literature that observation may be an effective tool for improving the quality of the teaching and learning process if applied professionally and methodically (Coe, 2014; Schoenfeld, 2012; MacMahon et al., 2007; Crowe, 2001). Based on this concept of classroom observation, observers in this study were trained to implement a new method to provide teachers with constructive feedback and give teachers ample opportunity to reflect on their performance, discover their areas for development, as well as support in the implementation of the suggested actions.

\subsection{The Classroom Observations in the English Language Center}

The administrators conduct classroom observations in the Colleges of Technology in the Sultanate of Oman. In the English Language Center (ELC) of one of these colleges where this study was carried out, observations are performed by the head of the center and two heads of sections. These observers have not previously been trained for this process which can cause some predictable difficulties.

They implement observations using an assessment checklist with scores of 1 to 5 . The observers monitor the lessons and give the teachers grades that are commensurate with their performance in that lesson from their point of view. Sometime after the observation, a feedback session is planned where the teacher and the observers meet to discuss his performance and the grade obtained. When a teacher gets a grade less than 2.8 over 5 , he is given a notification message after which he will be visited again. If he does not improve his performance to receive a higher score than the mentioned average, he is often dismissed from work due to poor performance. 
Due to the lack of training for the observers and an existing system of evaluation from senior management, the aim of the classroom visits is to evaluate teachers' performance rather than the professional development of teachers or the improvement of the quality of the teaching and learning. The results of the classroom visits can sometimes be very negative such as the termination of contracts. This risk causes fear from the classroom observation process. This method of observation also prompted a number of teachers to resign or move to more stable and peaceful environments. Therefore, there was a need to have a better understanding of the factors in classroom observation in the particular work context where this study took place. The research question that was aimed to be studied is as follows:

What are the changes in teachers' and observers' perceptions of the classroom observation process and its implementation at the English Language Center following an intervention in the form of a training program?

Therefore, this study aims to improve the effectiveness of the classroom observation process in the English Language Center through a needs analysis, intervention and evaluation of the changes.

\section{Methodology}

This study was conducted in a College of Technology, one of the seven such institutions in the Sultanate of Oman. The aim of the study was to improve the effectiveness of the classroom observation process in this context. Therefore, the participants of the study were also selected from the staff working here. There were two groups of participants: administrators who conducted classroom observations and the teaching staff who the administrators observed. The teaching staff were mainly of foreign nationals and evaluative observations are seen as a determining factor on continuation or termination of work contracts.

For the current study, semi-structured interviews were chosen as the data collection tool in order to have a deep understanding of the classroom observation process from both perspectives; observers and the teaching staff. The research methodology was qualitative and exploratory in its nature and therefore, interviews were an appropriate way to collect necessary data. The questions were prepared by the researchers and checked by Ph.D. qualified specialists from the field of education for face and construct validity.

The study consisted of three main stages: pre-intervention, intervention and post-intervention stages.

\subsection{Pre-Intervention: Data Collection and Needs Analysis}

During the first stage, three interviews with observers and twelve interviews with teaching staff were conducted. These interviews were transcribed and then analyzed thematically using Nvivo 11 software. The data analyzed in this first stage were categorized in two main parts: perceptions about the classroom observation and elements of its implementation. The data collected in the first stage from semi-structured interviews revealed that the classroom observation process recommended in college policy was not followed (e.g., there was no preobservation conference). The results also indicated that there were concerns about the quality of the observations in the English Language Center. 
Comparing and contrasting the existing perceptions and implementation with the established international practices from research literature provided a useful needs analysis regarding the classroom observation conducted in this context. This comparison was used to develop an intervention in the form of a training program for the observers.

\subsection{Intervention}

The second stage consisted of the intervention. After identifying the needs of the participants, a training program was designed to bridge the gap between international best practices and the existing situation at the English Language Center (ELC). As a result, the training program aimed to enhance the effectiveness of implementing the classroom observation process in the English Language Centre.

The researcher designed the intervention using some of the training program materials that were applied to train the Senior English Language Teachers in the Ministry of Education in Oman. Some extra materials have been added and some modified to suit the training objectives and the participants' needs.

The training was carried out in the ELC as the workplace seemed to be the most convenient place to have such an activity. The sessions were held from February 20 to March 15 2019. The intervention was divided into two main parts; theory and practice. The theoretical part included 5 sessions for a total of 20 hours. For the practical part, three sessions were conducted for a total of 7.5 hours. The practical part was designed for practicing conducting the preobservation as well as post-observation stages.

The intervention was conducted by one of the researchers who was experienced in providing training programs for teachers during his career with the Ministry of Education. He was also a participant in an intensive training program for trainers to conduct similar observation training programs. For the trainees, the three administrators were trained from the English Language Center. Head of the center and heads of sections. All three administrators attended and actively participated in this training program.

\subsection{Post-intervention: Data Collection and Measuring Changes}

In the third and final stage of the research, the interviews conducted before the intervention were repeated with teachers and observers. The teachers were purposively selected among those who were observed after the training program for the observers. This allowed the researchers to compare the themes and responses before and after the intervention and identify any changes that occurred.

\section{Findings}

The aim of this study was to improve the effectiveness of the classroom observation process in context. Thus, an appropriate intervention was designed based on the needs identified in the first stage of the study. The intervention was followed up by interviews to identify what changes occurred both in the perceptions and the implementation of observations.

After analyzing the results of the semi-structured interviews of this study, the results indicated the emergence of two main themes: perceptions and implementation. Regarding perceptions, four main themes emerged from them: the perceived effectiveness of classroom observation, 
anxiety during and after observation, the role of teachers and the role of observers. On the other hand, the implementation theme included three subthemes, namely, pre-observation, whileobservation, and post-observation.

\subsection{The perception themes}

The results before the intervention indicated that the observers considered the classroom observation process as part of their routine tasks. The main purpose of conducting it is to evaluate the performance of teachers, to ensure that they carry out instructions and to correct their mistakes. As for the teachers, the classroom observation was only a process of assessing and judging their performance. Also, the teachers' answers indicated that they believe that the observers lack the competence and skills necessary to perform the classroom observation professionally.

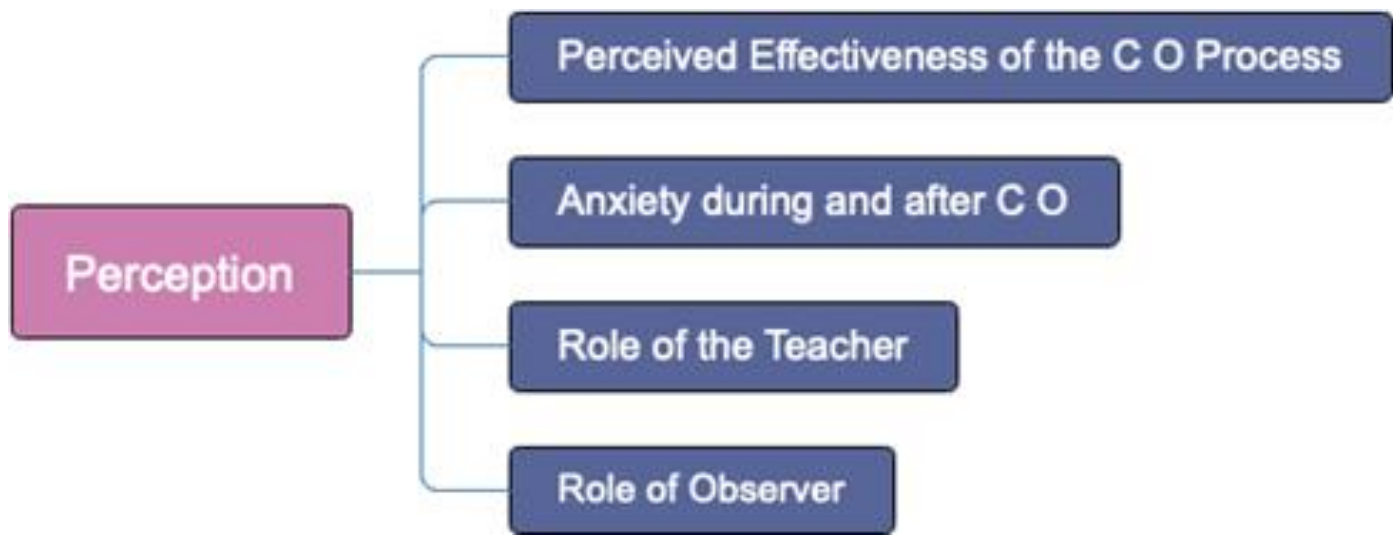

Figure 1. Main themes under perceptions from the interview data analysis

After the intervention, the perceptions of both observers and teachers on the classroom observation process changed. For observers, it became a tool to help teachers improve their performance. As for teachers, it was deemed as an opportunity to reflect on their performance and professional development. The teachers' view of the observers with regard to their competence also improved and teachers' confidence in the observers increased.

Another theme that emerged from the data analysis was anxiety of the teachers. The results before the intervention indicated that the teachers were anxious during the classroom observation process, in addition to their fear of post-observation conferences, the results of which might lead to termination of their work contracts. After the intervention, the anxiety rate decreased significantly, due to the change in the procedures and implementation of the classroom observation process.

The third and the fourth themes under the perceptions related to the role of the observers and the role of the teachers. The results before the intervention indicated that the observers took a dominant role, which was demonstrated more in the post observation conferences. In fact, the results indicated that the observers used the authoritative approach before the intervention. This has a direct impact on the role of teachers in the classroom observation process. The results showed that teachers played a passive role in this process. They were merely listening to the 
observers' comments and carrying out their instructions. However, after the intervention, the relationship and roles of teachers and observers changed. The post-observation conferences saw more participation and input from the teachers. Another important point to note here is that after the intervention the focus of the observers shifted from the teachers to the learning process.

\subsection{The Implementation themes}

Regarding the implementation aspect, as mentioned earlier, three main themes (before, during, and after) emerged to coincide with the three phases of the classroom observation process.

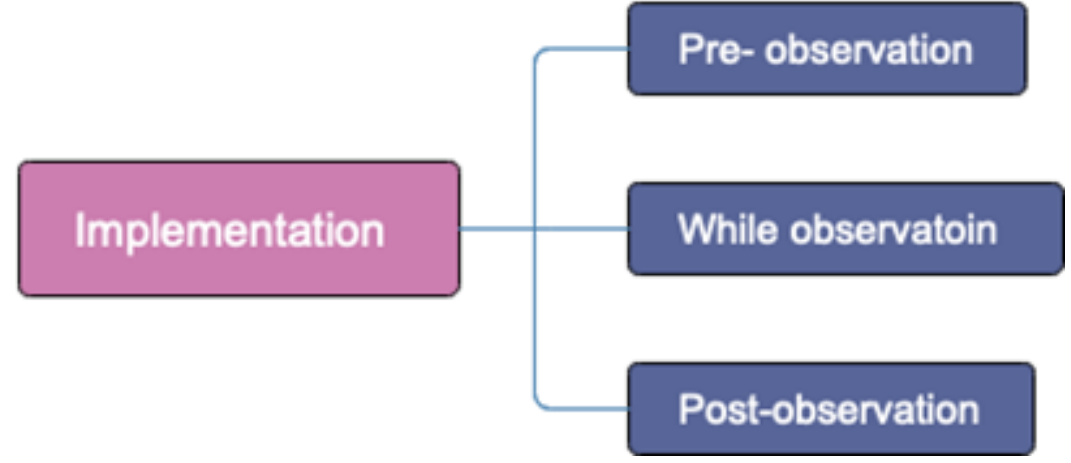

Figure 2. Main themes under implementation from the interview data analysis

Pre-observation stage was ignored prior to the intervention. The interview data indicated that the classroom observation process was carried out in a surprising manner, mostly without any prior notice to the teachers. No prior information was collected about the lessons, which led to a vague understanding for the observers when they practiced the actual observation stage. In addition, it caused anxiety and tension among the teachers. After the intervention, the preobservation stage started taking place. Information was exchanged by observers and teachers on critical issues such as the lesson aims and expectations.

Regarding the actual observations before the intervention, it was reported in the interviews that most teachers had one visit despite the observers' large number of classroom visits. This was due to time constraints, administrative responsibilities and a limited number of observers compared to the large number of teaching staff. The results also showed a conflict of opinion among teachers before the intervention regarding the frequency and number of class visits, as some preferred no visits, while others stated a need for multiple observations in different classes. Some teachers also mentioned that they preferred to have more than one observer per session. After the intervention and the change in the method and procedures of the classroom observation process, a major change was observed in the teachers' reactions. Their expressed levels of fear and anxiety decreased and some even stated that they wanted to have another classroom observation.

Finally, during the post-observation stage before the intervention, the observers believed that classroom observation was important because it enabled them to evaluate the performance of teachers. Therefore, the observers applied the traditional method known as the directive approach during the post observation conferences. Following this traditional supervision model, observers identified the teacher's strengths and weaknesses suggested appropriate solutions and then instructed teachers to implement them. Also, the teachers attributed great importance to the post-observation conferences. They considered it as a very worrying and crucial stage for them 
because the outcome would either enable them pass safely or could lead to the termination of their contracts. Therefore, they were always keen to carry out everything the observers asked of them, tried to satisfy and meet their needs even if they were not convinced of their comments. After the intervention, the observers adopted a non-directive approach (Freeman, 1982) in post lesson conferences, using a different and encouraging language that led to constructive feedback and professional development for teachers.

\section{Discussion}

\subsection{The perception themes}

\subsubsection{Perceived effectiveness of Class observation}

Interview findings collected before the intervention showed that the observers used the authoritarian approach while performing the classroom observation process. Perhaps the reason for their application of this approach is their conviction and belief in the traditional, top-down approach. The findings also indicated that the observers used the checklist as standard criteria for evaluating teachers' performance. This step negatively impacted teachers, as they considered the classroom observation process a tool used by inexperienced and incompetent people to assess and judge their performance. This finding aligns with Al-Mutairi (2016), who found that classroom observations in Kuwaiti schools are mainly implemented for teacher evaluation and not just for professional development.

However, after the intervention, the observers' perceptions of the classroom observation process changed, as the observers started using it as an instrument to improve teachers' performance. At the same time, the teacher begins looking at it as an opportunity for reflection and better performance. This change could result from the observers using a different approach to the classroom observation process after the intervention. Also, teachers receiving constructive feedback from observers positively changed the perception for both teachers and observers.

\subsubsection{Anxiety during and after the classroom observation}

Teachers' anxiety about the classroom observation process was one of the themes that changed significantly after the intervention. The results confirmed that the factor of fear and stress from the classroom observation process has vastly diminished. The reason for this decay is likely a change in the method and procedures of the classroom observation process. The implementation of the pre-lesson stage created a kind of reassurance among teachers, as they no longer feel that observers are targeting them. Therefore, teachers' perceptions of the classroom observation process have changed. This finding was consistent with what Bennington and Young (1983) stated about the importance of the role that pre-school plays in changing teachers' negative perceptions and removing their anxiety.

\subsubsection{The role of Observers and Teachers}

The role of teachers and observers in the classroom observation process was also one of the topics that changed significantly as observers abandoned the dominant role they played before the intervention and became a supportive role for teachers and focused on the learning process rather than the teacher. The reason for this change may be attributed to the observers' awareness after the intervention of the nature and role of the observer in the classroom observation process. This is supported by Carreiro, Guffey, and Rampp (1999). They advocate using a self-study method that focuses primarily on the professional development aspect of 
observation rather than evaluation. The same applies to teachers. After the intervention, the teachers realized the nature and importance of their role in the classroom observation process. They dominated the classroom observation process. They had a full opportunity to reflect on their performance, diagnose difficulties and suggest appropriate solutions. The noticeable change is due to the observers' adoption and application of the indirect approach. This is consistent with the findings of Glickman and Tamashiro (1980) of the importance of using a non-directive approach in post-class conferences.

\subsection{The Implementation themes \\ 4.2.1 Pre observation stage}

The lack of application of pr- observation stage has led to a tense relationship between teachers and observers as observers surprise teachers with their class visits. This method upsets most teachers because they were not prepared or perhaps because it made them feel unreliable and targeted. After the intervention, the pre-observation stage was applied, which significantly impacted the teachers and their relationship with the observers. This finding was consistent with what Tennant (2006) said about the necessity and importance of observers meeting with teachers before the actual teacher visit in the classroom. He believes that it is vital and directly affects the type of relationship between teachers and observers and the results of the classroom observation process in general.

\subsubsection{While observation}

The results before the intervention showed conflicting opinions of teachers, as some wanted to be visited more than once, while others stated that only one visit was sufficient. Some teachers also said that it is preferable to have more than one observer during the class visit. The reason for some people wanting more than one visit may be their fear of the result of one visit, and therefore they wished to have another opportunity to perform better and get a high rate. As for the teachers who request the presence of more than one observer during the class visit, this may be due to their desire to reduce the observer's bias. After the intervention, a kind of satisfaction appeared among the teachers from the classroom observation process. In general, there was a tendency and desire on the teachers to increase the number of classroom visits. The reason may be due to the willingness of teachers to improve their performance and reveal their actual level. This result came parallel to what some researchers mentioned about the importance of conducting more than one visit to teachers. For example, Klinger et al. (2008) argue that a single teacher visit is insufficient and does not reflect the level of the performance. This vision is also in line with the OECD (2013), which emphasized the need for three to eight formal and informal teacher visits annually.

\subsubsection{Post observation}

The results before the intervention showed that the observers applied the directive approach, while they applied the non-directive approach after the intervention in the post-lesson conferences. These results clearly show that the observers before the intervention believed that the directive approach was the best way to implement the classroom observation process. However, after the intervention, this concept changed for them. Consequently, they adopted the non-directive approach, which resulted in a noticeable change in how the classroom observation process was conducted by observers and diversity in teachers' performance. Applying the nondirective approach such as the language used has improved the relationship between teachers and 
observers. As a result, this led to a practical application of classroom observation. This method also enhanced teachers' self-efficacy, which affected their performance positively, as supported by Bandura (1977).

\section{Conclusion}

The results of this study can lead to a better understanding of the perceptions of both teachers and observers as well as knowledge of the underlying reasons for implementing the classroom observation process in a certain way. Based on the results of this study, it is possible to develop practical solutions to the problem of teachers' anxiety resulting from evaluation focused classroom observations. One of the most important ways to reduce such negative feelings and resulting poor performance was observed to be conducting pre-observations sessions. Although conducting pre-observation sessions needs more time to be dedicated, it has proven to be a great contributing factor to the success and effectiveness of the observations. Moreover, training on observation and feedback skills seem to activate teachers' role in this process and to contribute to their professional development. Although this study was conducted in a particular tertiary education institution, it can be replicated in other contexts to identify context specific conditions and develop responsive training interventions.

\section{About the couthers:}

Haroun M. Al Balushi is an English language lecturer at the University of Technology and Applied Sciences in Oman. Before joining the university, he worked in the Ministry of Education as an English language teacher, supervisor and a senior supervisor. He holds a Master degree in ELT from the European University of Lefke. He is currently a Ph.D. student at USIM in Malaysia. https://orcid.org/0000-0002-0498-847X

Dr. Noor Sazai graduated from the University of the United Kingdom with a PhD in (TESL). She did her masters and first degree at University of Malaya (UM). She joined USIM University (University of Sains Islam Malaysia) in 2007. Currently, she is teaching English Language and Technology in Education and also Practical Research. Her areas of interest and publications cover learning experiences, international education and teacher education. https://orcid.org/ 0000-0002-9558-3223

\section{References}

Almutairi, T. S. SH. S. A. (2016). Teacher Evaluation in Kuwait - Evaluation of the Current System and Consideration of Risk-Based Analysis as a Principle for Further Development, Durham theses, Durham University. Available at Durham E-Theses Online: http://etheses.dur.ac.uk/11857/

Bandura, A. (1997). Self-efficacy: The exercise of control. New York: W.H. Freeman and Company.

Carreiro, J., Guffey, J.S., \& Rampp, L. C. (1999). A Paradigm for the Training of Part-Time Teachers in Community Colleges. Retrieved from: https://eric.ed.gov/?id=ED436194

Chapman, O. (2007). Preservice Secondary Mathematics Teachers' Knowledge and Inquiry Teaching Approaches. In Woo, J. H., Lew, H. C., Park, K. S. \& Seo, D. Y. (Eds.). Proceedings of the 31st Conference of the International Group for the Psychology of Mathematics Education, Vol. 2, pp. 97-104. Seoul: PME. 
Duffy, F. M. (1997). Supervising schooling, not teachers. Educational Leadership, 54, ( 8), 7883.

Freeman, D. (1982). Observing Teachers: Three Approaches to In-Service Training and Development. TESOL Quarterly, 16(1), 21-28. doi:10.2307/3586560

Glickman, C. D., \& Tamashiro, R. T. (1980). Clarifying teachers' beliefs about discipline. Educational Leadership, 37(6), 459-464.

Glickman, C. D. (1990). Supervision of instruction: A developmental approach (2nd ed.). Boston: Allan and Bacon.

Goldhammer, R., Anderson, R. \& Krajewski, J. (1980). Clinical Supervision: Special Methods for the Supervision of Teachers. New York: Holt, Rinehart \& Winston.

Goldsberry, L. (1988). Three functional methods of supervision. Action in teacher education, 10(1), 1-10.

Gordove, E. (2002) Educational Management. Christ the King College. Calbayog City, Philippines.

Klinger, D. A., Shulha, L. M., \& DeLuca, C. (2008). Teacher evaluation, accountability, and professional learning: The Canadian perspective. Pensamiento educativo, 43(2), 209-222.

Marshall, K. (2009). Rethinking Teacher Supervision and Evaluation: How to Work Smart, Build Collaboration, and Close the Achievement Gap. Second Edition.

Mulyasa, E. (2007). Kepala sekolah profesional. Bandung: Remaja Rosdakarya. Bali, Indonesia.

OECD (2013), Teachers for the 21st Century: Using Evaluation to Improve Teaching, OECD publishing.

Olivia, P. F., \& Pawlas, G. E. (1997). Supervision for Today's Schools, 5th ed New York, NY.: Longman.

Pennington, M., \& Young, A. (1989). Approaches to Faculty Evaluation for ESL. TESOL Quarterly, 23(4), 619-646. doi:10.2307/3587535

Zuzovsky, R. (2009). Teachers' qualifications and their impact on student achievement: Findings from TIMSS 2003 data for Israel. IERI Monograph Series. Issues and Methodologies in Large-Scale Assessments, 2, 37-62.

Tennant, A. (2006). Key issues in classroom observation. IATEFL VOICES, 191, (8).

Wilcox, B. (2000). Making School Inspection Visits More Effective: The English Experience. Paris: UNESCO

Wragg, E.C. (1999). An Introduction to Classroom Observation and Class Management in Primary Schools. Published in April 2001 by Roultledgefalmer. 